\title{
Altas habilidades/superdotação no contexto das políticas nacionais de educação especial (1994 e 2008): pontos e contrapontos
}

Rosemeire de Araújo Rangni é bacharela em Direito, pedagoga, mestra em Educação, especialista em dotados e talentosos, doutoranda em Educação Especial do PPGEES-UFSCAR. Docente do Instituto Superior de Educação Vera Cruz.

\section{Contato: rose.rangni@uol.com.br}

Maria da Piedade Resende da Costa é psicóloga e fonoaudióloga. Docente do PPGEES-UFSCAR.

Contato: piedade@ufscar.br

\section{Resumo}

0 desconhecimento da temática das altas habilidades/superdotação, pelos profissionais da educação, gera a exclusão desses educandos, apesar do dever legal de atendê-los. Este artigo apresenta as altas habilidades/superdotação na legislação brasileira contextualizando as duas Políticas Nacionais de Educação Especial, de 1994 e 2008.

Palavras-chave: altas habilidades; superdotação; educação especial; legislação; exclusão.

\section{Abstract}

The unknowledgement of the giftedness theme by the educational professionals creates the exclusion of the gifted students in spite of the legal obligation to provide them. This article presents the giftedness in the Brazilian educational laws in the context of the two National Special Education Politics (1994 and 2008).

Keywords: Giftedness; special education; law; exclusion. 


\section{Introdução}

Tendo em vista os esforços implementados na legislação brasileira, a superdotação ainda é considerada como categoria de menor importância na Educação Especial. Prova disso são os ínfimos números de matrículas registrados no Censo Escolar comparados aos educandos matriculados em outras categorias de necessidades especiais.

Durante o período de 1994 aos dias atuais, vigoram duas políticas de Educação Especial: a Política Nacional de Educação Especial (1994), que tinha como pressuposto integrar os alunos portadores de necessidades educativas especiais ${ }^{1}$ na escola regular, e as Políticas Nacionais de Educação Especial na Perspectiva da Educação Inclusiva (2008), com objetivos de incluir na escola regular os educandos com necessidades educacionais especiais (NEE)2.

Mesmo com todo aporte legal, a incidência menor do alunado com altas habilidades identificado nas escolas remete à falta de políticas públicas, contrariando as recomendações legais, aos preconceitos e rejeições que essa parcela de sujeitos tem passado no decorrer de sua vida escolar.

Este artigo visa expor uma breve reflexão sobre o tema altas habilidades/superdotação à luz da legislação, mais especificamente a partir de 1994, quando da aprovação das Políticas Nacionais de Educação Especial, remetendo até a atual Políticas Nacionais de Educação Especial na Perspectiva da Educação Inclusiva, de 2008.

\section{Movimentos legais iniciais}

Em 1967 foi criado no Ministério de Educação e Cultura (MEC) uma comissão para estabelecer critérios, identificar e atender os superdotados (Novaes, 1979, p. 80).

O Departamento de Educação Complementar do MEC realizou na Universidade de Brasília, em 1971, o Seminário sobre Superdotados, no qual se reuniram especialistas de todo o Brasil tendo, como objetivo principal [...] "proceder a um levantamento sobre a

1. Termo utilizado na Política Nacional de Educação Especial (1994).

2. Termo utilizado nas Políticas Nacionais de Educação Especial na Perspectiva da Educação Inclusiva (2008). situação do superdotado no país. Os trabalhos apresentados 
foram de alto nível e, no final, foram apresentadas as conclusões e recomendações", segundo Novaes (1979, p. 80).

Pode-se dizer, em termos de legislação, que os superdotados no Brasil aparecem pela primeira vez na Lei de Diretrizes e Bases 5.692/71, no artigo $9^{\circ}$, que apontava:

\footnotetext{
Os alunos que apresentarem deficiências físicas ou mentais, os que se encontrarem em atraso considerável quanto à idade regular de matrícula e os superdotados deverão receber tratamento especial, de acordo com as normas fixadas pelos competentes Conselhos de Educação.
}

Com esse cômputo legal obtido pelos superdotados, o ano de 1971 foi marco importante para implementação da educação em prol desses sujeitos. Os Conselhos de Educação deveriam fixar normas para a inclusão dos superdotados na Educação Especial e essa recomendação, que representou a transferência de responsabilidade do governo federal aos Conselhos, permitiu que a medida fosse diluída e poucos Estados da Federação tiveram iniciativas nesse sentido, dado o número ínfimo de educandos atendidos.

Guenther (2001, p. 38) menciona que a legislação brasileira delega, na área de Educação, aos Estados e Municípios o estabelecimento de suas próprias políticas e diretrizes, "o que não tem sido benéfico para alunos mais capazes". A referida autora acrescenta que "quanto mais os órgãos centrais se esforçam para clarear atitudes, obrigações e tarefas concretas em relação à educação especial, mais se observa uma espécie de 'jogo de empurra' em relação à criança bem-dotada".

Pérez (2006) salienta que, em nível estadual, o atendimento aos "portadores de deficiências" e "superdotados" já era contemplado nas Constituições Estaduais de 1989 em três estados da Região Sul do Brasil: Paraná, Santa Catarina e Rio Grande do Sul.

Da recomendação da LDB 5.692/71 às constituições estaduais configura-se um período longo em que os altos habilidosos/ superdotados estiveram à margem de ações legais.

A partir das recomendações da Declaração de Salamanca (Brasil, 1994), da qual o país é signatário, começam a ocorrer discussões no sentido de uma escola que acolhesse todos, sem distinção de suas singularidades. A referida Declaração aumenta o leque de necessidades educacionais especiais, elencando os superdotados quando enfatiza que: 


\begin{abstract}
O princípio que orienta esta Estrutura é o de que escolas deveriam acomodar todas as crianças independentemente de suas condições físicas, intelectuais, sociais, emocionais, linguísticas ou outras. Aquelas deveriam incluir crianças deficientes e superdotadas, crianças de rua e que trabalham, crianças de origem remota ou de população nômade, crianças pertencentes a minorias linguística étnicas ou culturais, e crianças de outros grupos desavantajados ou marginalizados (Item 3, p. 3, grifo nosso).
\end{abstract}

No ano de 1994 as Políticas de Educação Especial são aprovadas, tendo como base a Lei de Diretrizes e Bases 5.692/71, ainda em vigência. Vigorava, naquela época, o conceito de integração. Bueno $(1999$, p. 2) assinala que "a integração partia do pressuposto de que o problema residia nas características das crianças excepcionais".

Para Carvalho (2004, p. 28), que esteve à frente da construção das Políticas de 1994, o verdadeiro significado da integração, como paradigma, tanto na sociologia como na psicologia social "traduz-se por interação, por relações de reciprocidade". A referida autora acrescenta as críticas que são feitas ao uso do termo integração sem levar em conta o conceito implícito dos processos interativos no termo. Também critica os que encaram a integração como sinônimo de serviços educacionais nos quais só se dependia da movimentação do aluno, "num ranço da meritocracia positivista", salienta.

No entendimento do que era Política Nacional de Educação Especial, a referida legislação também trazia orientações que sugeriam ações, inclusive explicando quem deveria ser atendido como portadores de necessidades educativas especiais.

\footnotetext{
(...) a ciência e a arte de estabelecer objetivos gerais e específicos, decorrentes da interpretação dos interesses, necessidades e aspirações de pessoas portadoras de deficiências, condutas típicas (problemas de condutas), e de altas habilidades (superdotadas), assim como de bem orientar todas as atividades que garantam a conquista e a manutenção de tais objetivos (Brasil, 1994, p. 7).
}

Os superdotados eram definidos na Política Nacional de Educação Especial de 1994 desta maneira: "Notável desempenho e elevada potencialidade em qualquer dos seguintes aspectos isolados ou combinados: capacidade intelectual geral; aptidão acadêmica específica; pensamento criativo ou produtivo; capacidade de liderança; talento especial para artes e capacidade psicomotora" (Brasil, 1994, p. 13). 


\section{A nova Lei de Diretrizes e Bases e a superdotação}

Dois anos depois, surge a nova Lei de Diretrizes e Bases da Educação Nacional (LDBN, 9.394/ 96), que revoga a 5.692/71, e a Educação Especial consolida-se, no Artigo 58, como modalidade de educação escolar.

No artigo 59, II, os superdotados são mencionados da seguinte forma: "terminalidade específica para aqueles que não puderem atingir o nível exigido para a conclusão do ensino fundamental, em virtude de suas deficiências, e aceleração para concluir em menor tempo o programa escolar para os superdotados" (grifo nosso). Ainda, no mesmo Artigo, IV, aponta:

\footnotetext{
educação especial para o trabalho, visando sua efetiva integração na vida em sociedade, inclusive condições adequadas para os que não revelarem capacidade de inserção no trabalho competitivo, mediante articulação com os órgãos oficiais afins, bem como para aqueles que apresentam uma habilidade superior nas áreas artísticas, intelectual ou psicomotora.
}

Em contraposição aos pressupostos da inclusão, promovidos pela Declaração de Salamanca (Brasil, 1994), na época da promulgação da LDBN 9.394/96 estava em vigência a Política Nacional de Educação Especial, de 1994, que utilizava o conceito de integração, compreendido como:

\footnotetext{
processo gradual e dinâmico que pode tomar distintas formas de acordo com as necessidades e habilidades dos alunos. A integração educativa escolar refere-se ao processo de educar-ensinar, no mesmo grupo, as crianças com e sem necessidades educativas especiais, durante uma parte ou na totalidade do tempo de permanência da escola (p. 18).
}

Muitas críticas foram feitas à integração no tocante à adaptação do aluno ao sistema escolar, ao contrário do conceito de inclusão, que preconiza o ajuste do sistema educacional às necessidades especiais dos educandos.

Discussões à parte, o fato é que os superdotados nunca deixaram de ser integrados, quer sob o contexto integrativo ou inclusivo, pelos menos fisicamente, na escola regular, mantendo-se invisíveis quanto ao atendimento de suas necessidades especiais em ambos os contextos.

0 Parecer 17/2001 que subsidia a Resolução n 02/2001, Diretrizes Nacionais para Educação Especial na Educação Básica, é enfático quanto à dificuldade de aceitação, como se pode observar: 


\begin{abstract}
Além desse grupo, determinados segmentos da comunidade permanecem igualmente discriminados e à margem do sistema educacional. É o caso dos superdotados, portadores de altas habilidades, "brilhantes" e talentosos que, devido a necessidades e motivações específicas incluindo a não aceitação da rigídez curricular e de aspectos do cotidiano escolar - são tidos por muitos como trabalhosos e indisciplinados, deixando de receber os serviços especiais de que necessitam, como por exemplo o enriquecimento e aprofundamento curricular. Assim, esses alunos muitas vezes abandonam o sistema educacional, inclusive por dificuldades de relacionamento (Brasil, 2001, p. 7).
\end{abstract}

A Resolução $n^{\circ}$ 02/2001, Artigo $5^{\circ}$, III, traz a definição para altas habilidades/superdotação como sendo "grande facilidade de aprendizagem que os leve a dominar rapidamente conceitos, procedimentos e atitudes".

Nota-se que, a partir dessa Resolução, houve um acréscimo significativo no atendimento aos educandos com NEE. Em 2001 foram atendidos 323.399 , em 2003, o número de matrículas evoluiu para 500.375 (Rangni, 2005, p. 99). 0 Censo Escolar/2006 indicou 700.624 alunos. Nesse cenário de evolução de matrículas, os superdotados se encontravam assim:

\begin{tabular}{|c|c|c|c|c|c|c|c|}
\hline 1996 & 1997 & 1998 & 1999 & 2000 & 2001 & 2002 & 2003 \\
\hline 490 & 1.724 & 1.187 & 1.228 & 454 & 692 & 625 & 1.675 \\
\hline
\end{tabular}

Fonte: MEC/INEP/SEEC/2004 apud Rangni (2005).

A evolução de matrículas apresentadas é ínfima se comparada com a probabilística da Organização Mundial da Saúde, 3,5\% a 5\% de alunos serem superdotados contemplando apenas os domínios verbal e lógico-matemático ou percentuais de $10 \%$ apresentados por Gagné (2010) ou, ainda, $15 \%$ a $20 \%$ pontuados por Renzulli (1986). 0 Censo Escolar (Brasil, 2006) apresentou 2.796 matrículas de altos habilidosos/superdotados em todo o país.

Em 2008, a Política Nacional de Educação Especial (Brasil, 1994) dá lugar às Políticas Nacionais de Educação Especial na Perspectiva da Educação Inclusiva (Brasil, 2008), que preconizam o acesso, a participação e a aprendizagem dos alunos com deficiência, transtornos globais do desenvolvimento e altas habilidades/ superdotação nas escolas regulares.

As Políticas Nacionais de 2008 redirecionam quem são os educandos com necessidades educacionais especiais e definem os altos habilidosos/superdotados como sendo: 
Alunos com altas habilidades/superdotação demonstram potencial elevado em qualquer uma das seguintes áreas, isoladas ou combinadas: intelectual, acadêmica, liderança, psicomotricidade e artes, além de apresentar grande criatividade, envolvimento na aprendizagem e realização de tarefas em áreas de seu interesse (Brasil, 2008 p. 9).

As definições praticamente se mantêm nas duas Políticas, trazendo, contudo, a psicomotricidade em vez de capacidade psicomotora. Aquela terminologia se configura mais ampla porque a psicomotricidade envolve as aquisições cognitivas, orgânicas e afetivas, enquanto o "psicomotor" abarca mente e corpo sem abranger o afetivo. Portanto, segundo a Sociedade Brasileira de Psicomotricidade, a psicomotricidade é "um termo empregado para a concepção de movimento organizado e integrado, em função das experiências vividas pelo sujeito cuja ação é resultado de sua individualidade, sua linguagem e sua socialização". No entanto, segundo Santos (s.d), o termo psicomotor pode ser o qualificativo de psicomotricidade.

0 atendimento educacional especializado, segundo as Políticas Nacionais de Educação Especial na perspectiva da Educação Inclusiva (Brasil, 2008), deve garantir:

- Transversalidade da educação especial desde a educação infantil até a educação superior;

- Atendimento educacional especializado;

- Continuidade da escolarização nos níveis mais elevados do ensino;

- Formação de professores para o atendimento educacional especializado e demais profissionais da educação para a inclusão escolar;

- Participação da família e da comunidade;

- Acessibilidade urbanística, arquitetônica, nos mobiliários e equipamentos, nos transportes, na comunicação e informação; e

- Articulação intersetorial na implementação das políticas públicas (Brasil, 2008, p. 8).

Um dos pontos convergentes das duas políticas aqui apresentadas é a formação de profissionais para a tarefa de identificação e atendimento a esses educandos, que se constitui 
no ponto crucial para que os educandos com altas habilidades/ superdotação saiam da situação excludente em que se encontram.

A Política de Educação Especial, de 1994, trazia, em relação à formação desses profissionais, como diretrizes gerais:

\footnotetext{
Produzir, em parceria com órgãos de ensino superior, amplo programa de formação e/ou especialização de recursos humanos na área de educação especial; capacitar e apoiar recursos humanos do ensino regular para o atendimento educacional aos portadores de deficiências, de condutas típicas e de altas habilidades; valorizar social e profissionalmente o grupo magistério, por meio de programas de formação permanente que estimulem a melhoria do trabalho docente (Brasil, 1994, p. 59-60).
}

\section{A formação de professores}

Porém, a questão é: quem formará esses profissionais? Sabe-se que os cursos de graduação (Pedagogia e Licenciaturas) não cristalizam conhecimento da temática, e os cursos de pós-graduação em nível de especialização para essa área são quase inexistentes. Perez (2006, p. 184) pontua a necessidade da formação de recursos humanos para atuar com as altas habilidades/superdotação e avançar de forma congruente com a legislação: [...] "Esses órgãos formadores devem assumir esse compromisso, contribuindo com a promoção de cursos, o incentivo e desenvolvimento de pesquisas, a produção, divulgação e publicação do conhecimento científico e a oferta de serviços de extensão". Dessa forma, a formação dos profissionais, em especial os que trabalham diretamente com os alunos, deveria dedicar um olhar cuidadoso para essa parcela de educandos em suas áreas de talentos e em suas singularidades.

Sobre o contexto da formação dos professores, Alencar e Fleith (2006) assinalam:

\footnotetext{
[... é inegável que boa educação para todos não significa uma educação idêntica para todos. Por esta razão, o professor deve estar atento no sentido de propiciar uma educação de boa qualidade, levando em conta as diferenças individuais e encorajando o desenvolvimento dos talentos, competências e habilidades diversas (p. s/n).
}

As Políticas Nacionais de Educação Especial na Perspectiva da Educação Inclusiva (Brasil, 2008) é um documento recente. Porém, espera-se que suas recomendações não levem o longo período que a Política Nacional de Educação Especial, de 1994, levou 
para atingir os alunos altos habilidosos/superdotados no Brasil. Carvalho $(2008$, p. 8$)$ assinala que:

\begin{abstract}
[...] na Política Nacional de Educação Especial, na perspectiva da Educação Inclusiva, documento apresentado pelo MEC em janeiro de 2008 e que ainda não foi o suficientemente analisado nos sistemas educacionais (ou porque não houve tempo hábil para tal análise crítica ou porque ainda não chegou ao conhecimento de todos os professores de nossos brasis: um país de dimensões continentais e caracterizado pela diversidade).
\end{abstract}

As Políticas Nacionais de Educação Especial na Perspectiva da Educação Inclusiva (Brasil, 2008) notadamente orientam ações no âmbito nacional, direcionando formalização aos Estados e Municípios às suas concepções. Com isso, legislações estaduais e municipais são formuladas, configurando-se como adaptações conjunturais políticas e administrativas que acabam levando longo tempo para serem levadas a efeito.

Em relação ao atendimento, o Decreto 6.571, de 2008, dispõe sobre o atendimento educacional especializado (AEE) e ratifica o preconizado nas Políticas Nacionais (Brasil, 2008), no artigo $1^{\circ}$, que os alunos com altas habilidades/superdotação recebam tal atendimento. 0 artigo $3^{\circ}$ garante apoio técnico e financeiro para o AEE e que atendam os objetivos previstos, dentre eles a formação de profissionais: "II - formação continuada de professores para o atendimento educacional especializado; III - formação de gestores, educadores e demais profissionais da escola para a educação inclusiva".

No entanto, apesar da recomendação do AEE, tanto nas Políticas Nacionais de 2008 quanto no Decreto, anteriormente mencionado, aos educandos que possuem altas habilidades/superdotação, há poucas ações nesse sentido. A recomendação de atender e como atender essa parcela de educandos era sugerida desde a Política Nacional, de 1994 (p. 53), que assinalava:

\footnotetext{
Criação e desenvolvimento de programas diversificados de enriquecimento e aprofundamento curricular para os portadores de altas habilidades; Implantação de programas diversificados, onde qualquer aluno possa trabalhar suas capacidades latentes, desenvolvendo-as em altas habilidades, mesmo que se trate de educandos com deficiência e condutas típicas (Brasil, 1994).
}

Essa menção carrega em seu bojo a possibilidade da dupla necessidade educacional especial em um só aluno. 
O Censo Escolar, em 2009, apresenta 5.637 matrículas de educandos com altas habilidades/superdotação (Del Pretto, 2010). Apesar da duplicação (101\%) de 2006 a 2009, ainda os educandos mais capazes estão abaixo do número esperado de identificação e atendimento apropriados.

A Educação Inclusiva é um novo paradigma, um movimento a ser compreendido e enfrentado pelos gestores políticos educacionais, profissionais da educação e familiares que podem, e devem, garantir o reconhecimento, desenvolvimento e permanência dos altos habilidosos/superdotados nas escolas de todo o país.

\section{Considerações finais}

As matrículas de alunos com necessidades especiais tiveram um crescimento expressivo, o que significa que o sistema educacional brasileiro está acolhendo esses educandos, apesar das dificuldades enfrentadas pelo sistema escolar regular.

No cômputo legal, há adequação da legislação acerca da inclusão de educandos com necessidades especiais e, especialmente, as altas habilidades/superdotação, o que denota a influência das Políticas Nacionais de Educação Especial (Brasil, 1994) e das Políticas Nacionais de Educação Especial na Perspectiva da Educação Inclusiva (Brasil, 2008) implementadas pelo Governo Federal.

0 número ainda ínfimo de matrículas dos educandos com altas habilidades/superdotação denota que estão invisíveis à identificação e ao atendimento, apesar de fisicamente integrados.

Nota-se, também, que a prioridade do atendimento educacional se encontra concentrada nas categorias das deficiências e síndromes, apesar de as altas habilidades/superdotação ser contempladas, desde 1971, na Lei de Diretrizes e Bases 5.692, terem permanecido na LDBN 9.394, de 1996 e, posteriormente, nos documentos referentes à Educação Especial e Inclusiva. 0 sistema escolar, principalmente do sistema público, não está atingindo os objetivos legais de atender essa parcela de sujeitos. Assim sendo, espera-se que os educandos com potenciais superiores que estão aos milhares "integrados" e invisíveis nas escolas do Brasil tenham seus direitos respeitados conforme o escrito na legislação. 


\section{REFERÊNCIAS}

ALENCAR, E. M. L. S.; FLEITH, D. S. A atenção ao aluno que se destaca por um potencial superior. Revista do Centro de Educação, $n^{0} 27$, Santa Maria, 2006. Disponível em <http://coralx.ufsm.br/revce/ ceesp/2006/01/a4.htm>. Acesso em 05/10/2010.

BRASIL. Ministério da Educação e do Desporto/ Secretaria de Educação Especial. Política Nacional de Educação Especial. Educação Especial. Um direito assegurado. Livro 1, 1994.

Declaração de Salamanca. Disponível em <http://potal.mec. gov.br/seesp/arquivos/pdf/salamanca.pdf>. Acesso em 16/07/2010.

. Lei de Diretrizes e Bases da Educação Nacional. Lei n 9.394, de 20 de dezembro de 1996. Brasília: Diário Oficial da União, 23 de dezembro de 1996.

Parecer CNE/CEB n 17/2001. Diretrizes Nacionais para a Educação Especial na Educação Básica. Disponível em <http://portal. mec.gov.br/cne/arquivos/pdf/CEB17_2001.pdf>. Acesso em 16 jul. 2010.

- Conselho Nacional de Educação. Câmara de Educação Básica. Resolução CNE/CEB nº 02 de 11 de Setembro de 2001. Diretrizes Nacionais para a Educação Especial na Educação Básica. Diário Oficial da União, 14 de setembro de 2001.

INEP. Censo Escolar, 2006. Disponível em: <http://www.inep. gov.br/basica/censo/default.asp >. Acesso em 20 jan. 2007.

Presidência da República, Casa Civil. Atendimento Educacional Especializado. Decreto $n^{0} 6.571$ de 17 de setembro de 2008.

MEC/SEESP. Políticas Nacionais de Educação Especial na Perspectiva da Educação Inclusiva, 2008 Disponível em: <http://portal. mec.gov.br/seesp/arquivos/pdf/politica.pdf>Acesso em 27 mar. 2010.

BUENO, J. G. S. Crianças com necessidades educativas especiais, política educacional e a formação de professores: generalistas ou especialistas? Revista Brasileira de Educação Especial, Marília, v. 3, n. 5, set. 1999, p. 7-27.

CARVALHO, R. E. Educação Inclusiva: com os pingos nos "is". Porto Alegre: Editora Mediação, 2004.

Cartografia do trabalho docente na e para a educação inclusiva. Revista @mbienteeducação, São Paulo, vol. 1, n. 2, p. 21-30, ago./dez. 2008. 
DEL PRETTO, B. M. L. Política Pública Educacional para as pessoas com altas habilidades/superdotação. IV Encontro Nacional do Conselho Brasileiro para Superdotação - CONBRASD, Curitiba, PR, 2010.

GAGNÉ, F. The Definition and Characterization of the Concept of Talent Developement. IV Encontro Nacional do Conselho Brasileiro para Superdotação - CONBRASD, Curitiba, PR, 2010.

GUENTHER, Z. C. Desenvolver capacidades e talentos: um conceito de inclusão. Petrópolis. RJ: Vozes, 2000.

NOVAES, M. H. Desenvolvimento psicológico do superdotado. São Paulo: Atlas, 1979.

RANGNI, R. A. O atendimento às pessoas com altas habilidades no Estado de São Paulo. Dissertação de Mestrado apresentada no Programa de Pós-Graduação em Educação da Universidade Cidade de São Paulo UNICID, 2005.

RENZULLI. J. S. The three ring conception of giftedness: a developement model for criative productivity. In: STERNBERG, R. J.; DAVIDSON, J. E. (Eds). Conception of giftedness. New York: Cambridge University Press, 1986, p. 53-92.

PEREZ, S. G. P. B. O atendimento educacional ao aluno com altas habilidades/superdotação na legislação da Região Sul do Brasil: os lineamentos para concretizar uma quimera. In FREITAS, S. N. (org.) Educação e altas habilidades/superdotação: a ousadia de rever conceitos e práticas. Santa Maria: Ed. Da UFSM, 2006.

SANTOS, R. P. Psicomotricidade. São Paulo: Course Pack, s/d.

SOCIEDADE BRASILEIRA DE PSICOMOTRICIDADE. Disponível em http:// www.psicomotricidade.com.br/apsicomotricidade.com.br>. Acesso em 11/02/2011. 